\title{
Urinary $\mathrm{LTE}_{4}$ Levels Identify Children with Tobacco Smoke Exposure At Risk for Asthma Exacerbation
}

\author{
Nathan Rabinovitch, MD ${ }^{1}$, Nichole Reisdorph, PhD $^{2}$, Lori Silveira, $\mathbf{M S}^{3}$, and Erwin W. \\ Gelfand, MD ${ }^{1}$ \\ ${ }^{1}$ Department of Pediatrics, National Jewish Health, Denver, CO \\ ${ }^{2}$ Department of Immunology, National Jewish Health, Denver, CO \\ ${ }^{3}$ Division of Biostatistics National Jewish Health, Denver, CO
}

\section{Abstract}

Background-Children with asthma exposed to second hand tobacco smoke (SHS) may be at higher risk for severe exacerbations but biomarkers of susceptibility to SHS exposure have not been previously reported.

Objectives-To assess the ability of urinary leukotriene $\mathrm{E}_{4}\left(\mathrm{uLTE}_{4}\right)$ levels to predict increased risk of severe asthma exacerbations requiring emergency room (ED) or urgent care (UC) visits.

Methods-44 schoolchildren with moderate to severe asthma receiving inhaled corticosteroids were followed for 5 months with repeated measurements of urine $\mathrm{LTE}_{4}$ and monitoring of ED and UC visits. SHS exposure status was determined by pre-study questionnaires and repeated measurements of urinary cotinine during the study.

Results-Nine of 20 (45\%) children with SHS exposure experienced a severe exacerbation requiring an ED or UC visit compared to three of 24 (12.5\%) children without significant SHS exposure (relative risk $=3.6,95^{\text {th }}$ confidence interval $(\mathrm{CI}) 1.1-11.5, \mathrm{p}=0.02$ ). Urinary $\mathrm{LTE}_{4}$ was a significant predictor of exacerbation risk in children exposed to SHS (area under the curve 0.85 , $\mathrm{p}=0.003$ ). Other predictors such as nighttime symptom frequency, pre and post bronchodilator lung function and exhaled nitric oxide were not related to exacerbations in this group. Urinary $\mathrm{LTE}_{4}$ levels at or above $106 \mathrm{pg} / \mathrm{mg}$ achieved $67 \%$ (6/9) sensitivity and 100\%(11/11) specificity for predicting children with SHS exposure who required an ED or UC visit.

Conclusions-Children exposed to SHS are at increased risk for severe asthma exacerbations despite use of inhaled corticosteroids. Urinary $\mathrm{LTE}_{4}$ levels identify children exposed to SHS at high risk for asthma exacerbations.

\section{Keywords}

asthma; biomarker; exacerbation; leukotriene E4; SHS

\section{Introduction}

Measurement of urinary leukotriene $\left(\mathrm{uLTE}_{4}\right)$ is a noninvasive method to assess changes in the rate of cysteinyl leukotriene (CysLT) production and excretion ${ }^{1,2}$. CysLTs are known to be key mediators and modulators in the pathogenesis of asthma ${ }^{3-6}$. Recent studies have found that leukotriene receptor antagonists are more effective in smokers ${ }^{7}$ or in children

Corresponding Author: Nathan Rabinovitch, MD National Jewish Medical Health 1400 Jackson Street Denver, CO 80206 Ph: (303) 398-1992 Fax: (303) 270-2189 rabinovitchn@ njhealth.org. 
exposed to tobacco smoke ${ }^{8}$, suggesting that the CysLT pathway may play an important role in mediating asthma health effects related to second hand smoke (SHS) exposure.

While multiple studies have reported that SHS is an important risk factor for increased asthma severity ${ }^{9-12}$, there are few if any studies to date that have explored variables that might help clinicians identify individual children at highest risk for exacerbation thereby warranting more aggressive environmental or therapeutic interventions. As health effects from SHS exposure might be related to inflammatory pathways related to CysLT production, we speculated that $\mathrm{uLTE}_{4}$ levels might also be a predictive biomarker of susceptibility to SHS exposure in children with asthma. As such, this analysis was performed to define and quantify the increased risk of severe exacerbations with SHS exposure in children receiving inhaled corticosteroids, to assess the value of $\mathrm{uLTE}_{4}$ in distinguishing children who are at increased risk when exposed to SHS, and to identify a predictive cut-off point for $\mathrm{uLTE}_{4}$. In this way, a proof-of-concept for the clinical application of $\mathrm{uLTE}_{4}$ as a biomarker of individual susceptibility to severe exacerbations related to SHS was tested.

\section{Methods}

Children ( $\mathrm{N}=44)$ with physician-diagnosed asthma, 6 to 15 years of age, at the Kunsberg School located on the campus of National Jewish Health, were followed for a $5 \frac{1}{2} 2$ month period (December 3, 2007 through April 17, 2008) as part of a NIH-funded protocol studying the mechanisms of SHS and air pollution exposure on asthma. Ethical and scientific approval for collection of these data was obtained from the National Jewish Health's Institutional Review Board before recruitment.

The Kunsberg School is a public elementary school designed to address the educational needs of children with significant asthma that interferes with regular school attendance and progress. Many of the children are classified as urban poor with approximately two-thirds of the students receiving Medicaid assistance. Most of the children receive their daily medication at schools supervised by school nurses thus minimizing compliance issues.

Up to 8 urine samples per subject were collected on consecutive school days during the first half of the study (until February 20, 2008). Urine was collected at approximately the same time each day (11:00 AM to 1:00 PM), spun down and frozen at minus 70 degrees Celsius after addition of protease inhibitors. They were subsequently batch assayed for $\mathrm{LTE}_{4}$ levels by mass spectrometry as previously described ${ }^{13}$. Cotinine levels were determined by immunoassay ${ }^{14}$. Urinary $\mathrm{LTE}_{4}$ levels were reported in picograms (pg) per milliliter and standardized per milligram ( $\mathrm{mg}$ ) of creatinine (measured by Jaffee methodology) in order to control for urine volume. Urinary cotinine levels were reported in nanograms (ng) per milliliter and standardized per mg of creatinine.

Fractional exhaled nitric oxide $\left(\mathrm{FE}_{\mathrm{NO}}\right)$ levels were measured at the same time as urine collection using a NIOX (Aerocrine AB, Solna, Sweden) $\mathrm{FE}_{\mathrm{NO}}$ analyzer at standard settings ${ }^{15}$ with the average of the 3 reproducible exhalations recorded. Once during the study period, children performed pre-and post-albuterol (4 puffs) spirometry (Jaeger, Hochberg Germany) after discontinuing short (4 hours previously) and long-acting (24 hours previously) bronchodilator treatment. Weekly questionnaires recorded emergency department (ED) or urgent care (UC) visits for asthma. This information was crosschecked with parents and school nurses. At study entry parents described children's demographic, allergic and asthma severity characteristics, as well as household smoking habits. 


\section{Statistical Analysis}

Demographic and asthma severity data obtained by questionnaire, lung function measurements and natural-log $(\ln )$ transformed biomarker measurements (mean of up to 8 repeated measurements for each child) were compared in children with SHS exposure (either parental smoking reported on pre-study questionnaire or cotinine levels above the mean for reported smoking households) and without SHS exposure. Categorical variables were compared using 2-tailed Fisher's exact tests while Student's t-tests were used for continuous variables. The association between SHS exposure and risk of requiring 1 or more ED or UC visits was determined by 2-tailed Fisher's exact test. For the primary analysis, logistic regression models with ED or UC visits as the outcome (vs. no exacerbation) and each child's mean (of up to 8 repeated measurements) $\mathrm{uLTE}_{4}$ level as the predictor were constructed for subgroups stratified by SHS exposure. For comparison, other potential predictors were also tested separately (secondary analyses). Urinary LTE $\mathrm{L}_{4}$ cut-off levels with the highest accuracy (true positive + true negatives divided by false positives + false negatives) were determined by receiver operator curves. Positive predictive values were calculated as true positives divided by (true positives + false positives) and negative predictive values were calculated as true negatives divided by (true negatives + false negatives). Statistical analyses were performed using JMP software (SAS, NC). Statistical significance was reported for $\mathrm{p}$-values below 0.05 .

\section{Results}

\section{Demographic and SHS Exposure Characteristics}

Table 1 summarizes demographic, allergic, medication and asthma severity data from the pre-study questionnaire as well as lung function and biomarker variables collected during the study (none of the lung function or biomarker measurements were collected during an asthma exacerbation). The cohort was predominantly male (64\%), African American (66\% had at least 1 African-American parent), reported a history of allergic-type symptoms with pet or pollen exposure, food allergies or eczema (84\%) and exhibited persistent nighttime asthma symptoms (56\%) despite receiving inhaled corticosteroids (ICS) (84\%). Based on their pre-study questionnaires, 15 out of 44 (34\%) children lived with at least 1 parent who smoked and $11(25 \%)$ lived with an indoor smoker. As questionnaire data tends to underestimate smoking exposure ${ }^{16}$, cotinine data were used to identify additional children with significant SHS exposure. Five of the 29 remaining children were classified as SHSexposed based on averaged cotinine levels above the mean for children whose parents reported smoking (i.e. $>\operatorname{logn} 3.1 \mathrm{ng} / \mathrm{mg}$ ) so that 20 of 44 children were finally classified as SHS-exposed and 24 of 44 as non-exposed. None of the children at the school were known smokers. Five children had cotinine/creatinine levels greater than 100. Three of these children had parents who reported smoking and 2 were regularly brought to school by relatives who smoked.

\section{SHS Exposure is Associated with Risk of Asthma Exacerbation}

Children with SHS exposure did not differ significantly from non-exposed children with the exception of significantly $(\mathrm{p}<0.001)$ higher cotinine levels and significantly $(\mathrm{p}=0.002)$ lower numbers of SHS-exposed children reporting any history of allergic-type symptoms with pet or pollen exposure, food allergies or eczema (Table I). Three of 24 (12.5\%) non-SHS exposed children and 9 out of 20 (45\%) SHS-exposed children required an ED or UC visit during the study period. Exposure to SHS was significantly $(\mathrm{p}=0.02)$ associated with an ED or UC visits (relative risk 3.6 (95 ${ }^{\text {th }}$ confidence interval 1.1-11.5)). 


\section{Urinary $\mathrm{LTE}_{4}$ is a Predictor of Exacerbation in Children Exposed to SHS}

Urinary $\mathrm{LTE}_{4}$ levels in SHS-exposed children were significantly (odds ratio (OR) 1.04 per unit increase in $\mathrm{uLTE}_{4}, \mathrm{p}=0.003$ ) associated with $\mathrm{ED}$ or UC visits such that children with higher mean $\mathrm{uLTE}_{4}$ levels were more susceptible than those with lower levels (Table II). None of the other predictors tested were significantly associated with increased risk in SHSexposed children and mean $\mathrm{uLTE}_{4}$ levels were not associated $(\mathrm{p}=0.81)$ with exacerbations in children not exposed to SHS (Table II). Five out of 24 (21\%) children in the non-SHS exposed group had uLTE 4 levels at or above $106 \mathrm{pg} / \mathrm{mg}$. One of 3 children (33\% sensitivity) with exacerbations in the non-exposed group had high uLTE $_{4}$ levels, and 17 of 21 children without exacerbations ( $81 \%$ specificity) had low $\mathrm{uLTE}_{4}$ levels. Lower percent-predicted $\mathrm{FEV}_{1}(\mathrm{p}=0.02)$ and older age $(\mathrm{p}=0.01)$ were associated with exacerbations in non-SHS exposed children but not in children exposed to SHS (Table II).

In SHS-exposed children, receiver operator curves identified the most accurate cutoff point for $\mathrm{uLTE}_{4}$ as at or above $106 \mathrm{pg} / \mathrm{mg}$ (Figure 1). Six (30\%) of the SHS-exposed children had mean $\mathrm{uLTE}_{4}$ levels at or above and $14(70 \%)$ below this cutoff. Six of the nine SHS-exposed children who required ED or UC visits had mean $\mathrm{uLTE}_{4}$ levels at or above $106 \mathrm{pg} / \mathrm{mg}(67 \%$ sensitivity) and 11/11 children who did not require an ED or UC visit had $\mathrm{uLTE}_{4}$ levels below $106 \mathrm{pg} / \mathrm{mg}$ (100\% specificity) (area under the curve 0.85, p=0.003) (Figure 1). Similar sensitivities, specificities and cut-off points for $\mathrm{ULTE}_{4}$ and ED or UC visits were observed if the SHS-exposed group was classified by reported smoking alone or by cotinine levels (at or above 5 or $10 \mathrm{mg} / \mathrm{mg}$ ) alone. Based on the prevalence of exacerbations in SHSexposed children in this cohort (45\%), the positive predictive value of the $\mathrm{uLTE}_{4}$ test was $100 \%$ while the negative predictive value was $78 \%$.

\section{Multivariable Model}

In an exploratory approach, forward stepwise regression ( $\mathrm{p}<0.05$ for inclusion) produced a 2- variable nominal logistic regression model with $\mathrm{uLTE}_{4}$ levels positively associated with exacerbations $(\mathrm{p}<0.0001)$ and $\mathrm{FEV}_{1}$ percent change with bronchodilator inversely associated with exacerbations $(\mathrm{p}=0.003)$. The area under the curve for this model was 0.96 , the negative log likelihood decreased from 9.4 to 5.1 and the R-squared value increased from 0.32 to 0.62 .

\section{Discussion}

Asthma is known to be a heterogenous disease with multiple triggers. This study highlights the importance of SHS exposure as an important environmental factor associated with severe exacerbations in children with asthma despite the use of inhaled corticosteroids. The relative risk for asthma exacerbation was increased by more than 3 times in children either living with parents who reported smoking or who demonstrated high mean cotinine levels. Approximately $45 \%$ of these SHS-exposed children required an ED or UC visit during the $5 \frac{1}{2}$ month study period compared to $12.5 \%$ of non-exposed children. Although SHSexposed children as a group were at higher risk, conventional markers of asthma severity did not work well in this population to predict which children would experience a severe asthma exacerbation. Neither nighttime symptom frequency, nor compromised lung function or airway inflammation as measured by mean $\mathrm{FE}_{\mathrm{NO}}$ levels were related to asthma exacerbations in children exposed to SHS. In contrast, mean uLTE $_{4}$ levels were shown to be strong predictors of risk with positive and negative predictive values of $100 \%$ and $78 \%$ respectively at a cut-off level at or above $106 \mathrm{pg} / \mathrm{mg}$.

The increased risk of exacerbation with SHS exposure occurred in a school setting where asthma status was closely monitored and controller medications such as ICS were regularly 
administered supporting earlier reports of tobacco smoke-related "steroid resistance" in children $^{17}$ and adults ${ }^{18}$. Possible mechanisms for this include decreased bioavailability of smaller ICS particles which interact with SHS particles ${ }^{19}$ and/or reductions in levels of histone deacytylase 2, a critical part of co-repressor complexes recruited by corticosteroids $^{20}$. Resistance to ICS controller therapy may, at least, partially explain the high prevalence of SHS exposure in this and other studies of children with undercontrolled asthma $^{21}$ supporting the value of a comprehensive exposure assessment in such children. This would include an objective measurement such as cotinine to identify a significant amount of underreported SHS exposure as seen in this study.

This study examined how mean $\mathrm{uLTE}_{4}$ levels in each child relate to risk of exacerbation in children chronically exposed to SHS. Some earlier reports have suggested that $\mathrm{ULTE}_{4}$ levels are increased immediately after smoking ${ }^{22}$. Similarly, in the Kunsberg children, daily $\mathrm{uLTE}_{4}$ levels increase transiently on the day of exposure to ambient particulate ${ }^{23}$ and to SHS (unpublished data) but then return to baseline or below on subsequent days. This transient increase and subsequent suppression explains why mean $\mathrm{uLTE}_{4}$ levels were not significantly different in SHS-exposed vs. non-SHS exposed children as mean levels should reflect chronic but not acute SHS exposure. Earlier work had shown that Kunsberg School children chronically exposed to significant SHS (as measured by mean urinary cotinine levels) demonstrated increased albuterol usage in association with daily increases in $\mathrm{uLTE}_{4}{ }^{8}$ suggesting increased receptor sensitivity to changes in $\mathrm{uLTE}_{4}$. We speculate that children with higher mean $\mathrm{uLTE}_{4}$ also have increased daily $\mathrm{uLTE}_{4}$ variability and that it is this high degree of variability together with increased receptor sensitivity to $\mathrm{uLTE}_{4}$ in children with chronic SHS exposure which is associated with an increased risk of acute exacerbation. Although it was previously assumed that CysLT effects occur predominantly through ligation of the CysLT 1 receptor by $\mathrm{LTC}_{4}, \mathrm{D}_{4}$ and less strongly by $\mathrm{LTE}_{4}{ }^{24}$, recent studies suggest that $\mathrm{LTE}_{4}$ alone may mediate multiple effects on asthma pathogenesis through $\mathrm{P} 2 \mathrm{Y}$ (12), an adenosine diphosphate receptor, and the CysLT (E) receptor ${ }^{25,26}$. Further timeseries analyses are planned to elucidate the acute effects of SHS on $\mathrm{uLTE}_{4}$ and on asthma exacerbations.

Besides providing insight on mechanisms of SHS-related health effects, the findings in this study could have important clinical implications. One of the major challenges in adult and childhood asthma is how to predict disease worsening so as to preempt severe asthma exacerbations. Reliance on symptom patterns or peak flow monitoring does not appear to provide sufficient warning of impending exacerbation ${ }^{27}$ perhaps because many patients with chronic asthma have poor symptom recognition while changes in peak flows are effortdependent and may be insensitive until later in the exacerbation process ${ }^{28}$. It has been suggested that measurement of biological markers of airway inflammation may provide a sensitive indicator of airway changes that occur early in the exacerbation process. The best studied example of this approach is the use of $\mathrm{FE}_{\mathrm{NO}}$, a surrogate measure of the eosinophilic airway response classically seen after allergen exposure, to guide the dosage requirement of inhaled corticosteroid (ICS) therapy and prevent exacerbations. In this context, after some initial positive results ${ }^{29}$, reports have been generally disappointing ${ }^{30}$ and the present recommendation is that the use of $\mathrm{FE}_{\mathrm{NO}}$ to tailor stepped-up therapy is not indicated ${ }^{31}$. Results from the present study imply that the predictive value of an individual biomarker may be diluted when applied to the general pediatric asthma population and that stronger associations are seen in subgroups with clear environmental triggers. Here, for example, high $\mathrm{uLTE}_{4}$ levels alone were not predictive of exacerbation risk in children not exposed to SHS. As such, these findings suggest that determining both exposure status and biomarker level may be necessary components for quantifying individual risk. In the scenario of a child with under-controlled asthma who is exposed to SHS and has high $\mathrm{uLTE}_{4}$ levels, a more aggressive approach to minimizing exposure or targeting airway sensitivity, for example by 
increasing controller medications, may be helpful to prevent exacerbations. Although an aggressive approach to limit SHS exposure should be a priority in all children with asthma, increased vigilance to even low level SHS exposure may be warranted in these highly susceptible children.

As in any observational study, selection bias is possible and a larger prospective trial will be necessary to confirm these results and clinical inference is most relevant to the predominant characteristics of the studied cohort, i.e. African-American school-aged children of lower socioeconomic status with moderate to severe asthma who were receiving daily inhaled corticosteroid therapy. This analysis was hypothesis-driven based on earlier work demonstrating that children exposed to tobacco smoke have increased susceptibility to $\mathrm{uLTE}_{4}$-related increases in rescue albuterol usage ${ }^{8}$. As such, the primary intention of this study was to test associations with $\mathrm{uLTE}_{4}$ levels. In subsequent exploratory analyses, a forward stepwise regression approach was utilized and produced a 2-variable model with $\mathrm{uLTE}_{4}$ levels positively associated with exacerbations and $\mathrm{FEV}_{1}$ percent change with bronchodilator inversely associated with exacerbations. One interpretation of these findings is that, at mean $\mathrm{uLTE}_{4}$ levels, children with higher post-bronchodilator $\mathrm{FEV}_{1}$ are less likely to have an exacerbation. A second possibility is that increased risk of exacerbation occurs in children with reduced lung function reversibility and more fixed airways disease. Given the exploratory nature of this 2-predictor model, we are cautious about interpreting its significance without further validation in a prospective hypothesis-driven study.

In summary, children in this study population exposed to SHS were at higher risk for an asthma exacerbation despite use of inhaled corticosteroids. Urinary $\mathrm{LTE}_{4}$ levels identified children in this study population with SHS exposure who experienced an exacerbation of their asthma requiring an ED or UC visit. A cut-off point for $\mathrm{uLTE}_{4}$ of $106 \mathrm{pg} / \mathrm{mg}$ achieved high predictive values while other more conventional predictors such as nighttime symptom frequency, pre-bronchodilator $\mathrm{FEV}_{1}$ and $\mathrm{FE}_{\mathrm{NO}}$ levels were unable to predict susceptibility in these children. This initial study identifies the potential for utilizing $\mathrm{uLTE}_{4}$ measurements to predict increased susceptibility in children with asthma exposed to SHS highlighting the need for timely and aggressive environmental and therapeutic interventions to minimize severe asthma exacerbations in these at-risk children. Further study is needed to assess the clinical feasibility of using $\mathrm{uLTE}_{4}$ measurements as a management tool in these children.

\section{Acknowledgments}

We thank Kate Marquart for following and collecting data daily from the schoolchildren, Michael Armstrong for performing LTE4 measurements, Ben Efaw for performing cotinine measurements, and Gretchen Hugen for formatting of the manuscript. We appreciate the kind assistance of the teachers, nurses and staff of the Kunsberg School and the children for participating in the study and making this analysis possible. Supported by NIH K23 ES015510-01

Grant funding: NIH/NIEHS K23 grant \# ES015510-01.

\section{Abbreviations}

(CysLT) cysteinyl leukotriene

(ED) emergency department

$\left(\mathrm{FEV}_{1}\right) \quad$ forced expiratory volume in 1-second

(FVC) forced vital capacity

$\left(\mathbf{F E}_{\mathbf{N O}}\right) \quad$ fractional exhaled nitric oxide 


$\begin{array}{ll}(\text { ICS }) & \text { inhaled corticosteroid } \\ \left(\text { LTE }_{4}\right) & \text { leukotriene } \mathrm{E}_{4} \\ (\mathbf{m g}) & \text { milligram } \\ (\mathbf{p p b}) & \text { parts per billion } \\ (\mathbf{p g}) & \text { picogram } \\ (\mathbf{S H S}) & \text { second hand smoke } \\ (\mathbf{U C}) & \text { urgent care }\end{array}$

\section{References}

1. Kumlin M. Measurement of leukotrienes in humans. Am J Respir Crit Care Med. 2000; 161:S102S106. [PubMed: 10673236]

2. Smith CM, Hawksworth RJ, Thien FC, Christie PE, Lee TH. Urinary leukotriene E4 in bronchial asthma. Eur Respir J. 1992; 5:693-9. [PubMed: 1321055]

3. Doucet MY, Jones TR, Ford-Hutchinson AW. Responses of equine trachealis and lung parenchyma to methacholine, histamine, prostanoids, and leukotrienes in vitro. Can J Physiol Pharmacol. 1990; 68:379-83. [PubMed: 2322894]

4. Busse W, Kraft M. Cysteinyl leukotrienes in allergic inflammation: strategic target for therapy. Chest. 2005; 127:1312-26. [PubMed: 15821210]

5. Gyllfors P, Kumlin M, Dahlén SE, Gaber F, Ehrs PO, Dahlen B. Relation between bronchial responsiveness to inhaled leukotriene D4 and markers of leukotriene biosynthesis. Thorax. 2005; 60:902-8. [PubMed: 16055619]

6. Rabinovitch N, Zhang L, Gelfand EW. Urine leukotriene E4 levels are associated with decreased pulmonary function in children with persistent airway obstruction. J Allergy Clin Immunol. 2006; 118:635-40. [PubMed: 16950282]

7. Lazarus SC, Chinchilli VM, Rollings NJ, Boushey HA, Cherniack R, Craig TJ, et al. Smoking affects response to inhaled corticosteroids or leukotriene receptor antagonists in asthma. Am J Respir Crit Care Med. 2007; 175:783-90. [PubMed: 17204725]

8. Rabinovitch N, Strand M, Stuhlman K, Gelfand EW. Exposure to tobacco smoke increases leukotriene E4-related albuterol usage and response to montelukast. J Allergy Clin Immunol. 2008; 121:1365-71. [PubMed: 18439662]

9. Couriel JM. Passive smoking and the health of children. Thorax. 1994; 49:731-734. [PubMed: 8091314]

10. Forastiere F, Corbo MG, Michelozzi P, Pistelli R, Agabiti N, Brancato G, et al. Effects of environment and passive smoking on the respiratory health of children. Int J Epidemiol. 1992; 21:66-73. [PubMed: 1544761]

11. Stoddard JJ, Miller T. Impact of parental smoking on the prevalence of wheezing respiratory illness in children. Am J Epidemiol. 1995; 141:96-102. [PubMed: 7817977]

12. Chilmonczyk BA, Salmun LM, Megathlin KN, Neveaux LM, Palomaki GE, Knight GJ, et al. Association between exposure to environmental tobacco smoke and exacerbations of asthma in children. N Engl J Med. 1993; 328:1665-1669. [PubMed: 8487825]

13. Armstrong M, Liu AH, Harbeck R, Reisdorph R, Rabinovitch N, Reisdorph N. Leukotriene-E4 in human urine: Comparison of on-line purification and liquid chromatography-tandem mass spectrometry to affinity purification followed by enzyme immunoassay. J Chromatogr B Analyt Technol Biomed Life Sci. 2009; 877:3169-74.

14. Muscat JE, Djordjevic MV, Colosimo S, Stellman SD, Richie JP Jr. Racial differences in exposure and glucuronidation of the tobacco-specific carcinogen 4-(methylnitrosamino)-1-(3-pyridyl)-1butanone (NNK). Cancer. 2005; 103:1420-1426. [PubMed: 15726545] 
15. Buchvald F, Baraldi E, Carraro S, Gaston B, De Jongste J, Pijnenburg MW, et al. Measurements of exhaled nitric oxide in healthy subjects age 4 to 17 years. J Allergy Clin Immunol. 2005; 115:1130-6. [PubMed: 15940124]

16. Cornelius MD, Goldschmidt L, Dempsey DA. Environmental tobacco smoke exposure in lowincome 6-year-olds: parent report and urine cotinine measures. Nicotine Tob Res. 2003; 3:333339. [PubMed: 12791528]

17. Cohen RT, Raby BA, Van Steen K, Fuhlbrigge AL, Celedón JC, Rosner BA, Strunk RC, Zeiger RS, Weiss ST, Childhood Asthma Management Program Research Group. In utero smoke exposure and impaired response to inhaled corticosteroids in children with asthma. J Allergy Clin Immunol. 2010; 126(3):491-7. [PubMed: 20673983]

18. Pedersen B, Dahl R, Karlstrom R, Peterson CG, Venge P. Eosinophil and neutrophil activity in asthma in a one-year trial with inhaled budesonide. The impact of smoking. Am J Respir Crit Care Med. 1996; 153:1519-1529. [PubMed: 8630596]

19. Invernizzi G, Ruprecht A, De Marco C, Mazza R, Nicolini G, Boffi R. Inhaled steroid/tobacco smoke particle interactions: a new light on steroid resistance. Respir Res. 2009; 10:48. [PubMed: 19519905]

20. Adenuga D, Yao H, March TH, Seagrave J, Rahman I. Histone deacetylase 2 is phosphorylated, ubiquitinated, and degraded by cigarette smoke. Am J Respir Cell Mol Biol. 2009; 40:464-73. [PubMed: 18927347]

21. Bracken M, Fleming L, Hall P, Stephout VN, Bossley C, Biggart E, et al. The importance of nurseled home visits in the assessment of children with problematic asthma. Arch Dis Child. 2009; 94:780-784. [PubMed: 19546102]

22. Fauler J, Frolich JC. Cigarette smoking stimulates cysteinyl leukotriene production in man. Eur J Clin Invest. 1997; 27:43-47. [PubMed: 9041376]

23. Rabinovitch N, Strand M, Gelfand EW. Particulate levels are associated with early asthma worsening in children with persistent disease. Am J Respir Crit Care Med. 2006; 173:1098-105. [PubMed: 16484676]

24. Fregonese L, Silvestri M, Sabatini F, Rossi GA. Cysteinyl leukotrienes induce human eosinophil locomotion and adhesion molecule expression via a CysLT1 receptor-mediated mechanism. Clin Exp Allergy. 2002; 32:745-750. [PubMed: 11994100]

25. Lee TH, Woszczek G, Farooque SP. Leukotriene E4: perspective on the forgotten mediator. J Allergy Clin Immunol. 2009; 124:417-21. [PubMed: 19482346]

26. Austen KF, Maekawa A, Kanaoka Y, Boyce JA. The leukotriene E4 puzzle: finding the missing pieces and revealing the pathobiologic implications. J Allergy Clin Immunol. 2009; 124:406-14. [PubMed: 19647860]

27. Covar RA, Szefler SJ, Zeiger RS, Sorkness CA, Moss M, Mauger DT, et al. Factors associated with asthma exacerbations during a long-term clinical trial of controller medications in children. $\mathrm{J}$ Allergy Clin Immunol. 2008; 122:741-7. [PubMed: 19014765]

28. Goldstein MF, Veza BA, Dunsky EH, Dvorin DJ, Belecanech GA, Haralabatos IC. Comparisons of peak diurnal expiratory flow variation, postbronchodilator $\mathrm{FEV}(1)$ responses, and methacholine inhalation challenges in the evaluation of suspected asthma. Chest. 2001; 119:1001-10. [PubMed: 11296161]

29. Smith AD, Cowan JO, Brassett KP, Herbison GP, Taylor DR. Use of exhaled nitric oxide measurements to guide treatment in chronic asthma. N Engl J Med. 2005; 352:2163-73. [PubMed: 15914548]

30. Szefler SJ, Mitchell H, Sorkness CA, Gergen PJ, O'Connor GT, Morgan WJ, et al. Management of asthma based on exhaled nitric oxide in addition to guideline-based treatment for inner-city adolescents and young adults: a randomised controlled trial. Lancet. 2008; 372:1065-72. [PubMed: 18805335]

31. Petsky HL, Cates CJ, Li AM, Kynaston JA, Turner C, Chang AB. Tailored interventions based on exhaled nitric oxide versus clinical symptoms for asthma in children and adults. Cochrane Database Syst Rev. 2008 CD006340. 
Clinical Implications

Urinary $\mathrm{LTE}_{4}$ may be helpful as a susceptibility biomarker to identify children exposed to SHS at high risk for severe asthma exacerbations despite use of controller therapies. 
Capsule Summary

Urinary $\mathrm{LTE}_{4}$ levels identified school children exposed to tobacco smoke who are at higher risk for asthma exacerbations. 


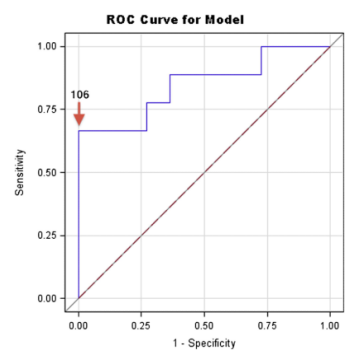

Figure 1.

Receiver operator characteristic curve indicating the sensitivity and specificity for predicting an ED or UC visit in children exposed to SHS. Specificity and sensitivity were $100 \%$ and $67 \%$ respectively at an $\mathrm{uLTE}_{4}$ level at or above $106 \mathrm{pg} / \mathrm{mg}$ (Area under the curve $=0.85$, $\mathrm{p}=0.003)$. 


\section{Table I}

Demographic, Asthma Severity and Biomarker Characteristics For Participants

\begin{tabular}{|c|c|c|c|c|}
\hline Characteristic & $\begin{array}{l}\text { All Subjects } \\
(\mathbf{N}=\mathbf{4 4})\end{array}$ & $\begin{array}{l}\text { ETS Exposed } \\
\text { (household smoker } \\
\text { or cotinine level } \\
\text { above ln } 3.1 \\
\text { ng/mg) } \\
(\mathbf{N}=\mathbf{2 0})\end{array}$ & $\begin{array}{l}\text { Not ETS } \\
\text { Exposed } \\
(\mathbf{N}=24)\end{array}$ & $\begin{array}{c}\text { P-value for Difference } \\
\text { ETS Vs no-ETS } \\
\text { Exposed }\end{array}$ \\
\hline Age, years & $10.1 \pm 2.3$ & $10.4 \pm 2.6$ & $9.8 \pm 2.0$ & 0.23 \\
\hline Height, inches & $55 \pm 5.9$ & $55.9 \pm 6.5$ & $54.2 \pm 5.4$ & 0.17 \\
\hline Male, n (\%) & $28(64 \%)$ & $13(65 \%)$ & $15(62.5 \%)$ & 1.0 \\
\hline African -American, n (\%) & $29(66 \%)$ & $14(70.0 \%)$ & $15(62.5 \%)$ & 0.75 \\
\hline Allergies, n (\%) & $37(84 \%)$ & $13(65 \%)$ & $24(100 \%)$ & $0.002^{* *}$ \\
\hline $\begin{array}{l}\text { Pre-bronchodilator } \mathrm{FEV}_{1} \% \\
\text { predicted, mean }+/-\mathrm{SD}\end{array}$ & $97.1 \pm 16.9$ & $94.7 \pm 15.2$ & $99.1 \pm 18.3$ & 0.80 \\
\hline $\begin{array}{l}\text { Pre-bronchodilator } \mathrm{FEV}_{1} / \mathrm{FVC} \text {, } \\
\text { mean }+/-\mathrm{SD}\end{array}$ & $80.8 \pm 9.6$ & $80.2 \pm 10.9$ & $81.3 \pm 8.5$ & 0.64 \\
\hline $\begin{array}{l}\mathrm{FEV}_{1} \% \text { change with } \\
\text { bronchodilator, mean }+/-\mathrm{SD}\end{array}$ & $10.5 \pm 7.7$ & $10.7 \pm 6.6$ & $10.4 \pm 8.9$ & 0.44 \\
\hline $\begin{array}{l}\text { Nighttime symptoms > } \\
\text { 2x/week, n (\%) }\end{array}$ & $24(54 \%)$ & $11(55 \%)$ & $13(54 \%)$ & 1.00 \\
\hline Inhaled corticosteroid, $\mathrm{n}(\%)$ & $37(84 \%)$ & $18(90 \%)$ & $19(79 \%)$ & 0.43 \\
\hline $\begin{array}{l}\text { Cotinine, } \mathrm{ng} / \mathrm{mg}(\ln ), \text { mean }+/- \\
\text { SD }\end{array}$ & $\begin{array}{l}35.0 \pm 69.2 \\
(2.1 \pm \underline{1.7)}\end{array}$ & $\begin{array}{l}72.4 \pm 90.2 \\
(3.5 \pm 1.4)\end{array}$ & $\begin{array}{l}3.9 \pm 3.9 \\
(0.9 \pm 0,9)\end{array}$ & $<0.001^{* *}$ \\
\hline $\mathrm{FE}_{\mathrm{NO}} \mathrm{ppb}(\mathrm{ln})$, mean +/-SD & $\begin{array}{c}25.8 \pm 23.2 \\
(2.9 \pm 0.8)\end{array}$ & $\begin{array}{c}27.2 \pm 23.9 \\
(3.0 \pm 0.8)\end{array}$ & $\begin{array}{c}24.6 \pm 23.0 \\
(2.9 \pm 0.8)\end{array}$ & 0.31 \\
\hline $\begin{array}{l}\text { Urine } \mathrm{LTE}_{4}, \mathrm{pg} / \mathrm{mg} \text { creatinine } \\
(\mathrm{ln}), \text { mean }+/-\mathrm{SD}\end{array}$ & $\begin{array}{l}90.9 \pm 57.8 \\
(4.3 \pm 0.6)\end{array}$ & $\begin{array}{l}84.7 \pm 58.1 \\
(4.2 \pm 0.8)\end{array}$ & $\begin{array}{l}96.1 \pm 58.4 \\
(4.4 \pm 0.5)\end{array}$ & 0.88 \\
\hline
\end{tabular}

* P-values calculated using 2-tailed Fisher's Exact Test (for categorical variables) or Student's T-Test (for continuous variables) **

$\mathrm{p}<0.01$ 
Table II

Associations with ED or UC visits in ETS and non-ETS Exposed Children

\begin{tabular}{|c|c|c|c|c|}
\hline Variable (unit) & $\begin{array}{c}\text { ETS Exposed } \\
\text { Odds ratio change per } \\
\text { category or per unit } \\
\text { increase in variable }\end{array}$ & p-value * & $\begin{array}{c}\text { Not ETS } \\
\text { Exposed } \\
\text { Odds ratio change per } \\
\text { category or per unit } \\
\text { increase in variable }\end{array}$ & p-value * \\
\hline Age (years) & 0.96 & 0.84 & 2.63 & $0.01^{* *}$ \\
\hline Height (inches) & 0.98 & 0.82 & 1.26 & 0.06 \\
\hline Male & 2.92 & 0.27 & Could not be calculated 1 & \\
\hline African -American & 0.28 & 0.20 & 0.25 & 0.27 \\
\hline Allergies & 1.14 & 0.89 & \multicolumn{2}{|c|}{ All children allergic } \\
\hline Pre-bronchodilator $\mathrm{FEV}_{1}(\%$ predicted $)$ & 0.97 & 0.31 & 0.91 & $0.02 * *$ \\
\hline Pre-bronchodilator $\mathrm{FEV}_{1} / \mathrm{FVC}(\%)$ & 1.005 & 0.89 & 0.92 & 0.25 \\
\hline $\begin{array}{l}\mathrm{FEV}_{1} \text { change with bronchodilator ( } \% \\
\text { predicted) }\end{array}$ & 0.92 & 0.27 & 1.11 & 0.17 \\
\hline Nighttime symptoms $>2 x /$ week & 1.04 & 0.96 & 1.82 & 0.64 \\
\hline Inhaled corticosteroid use & Could not be calculated ${ }^{2}$ & & 0.47 & 0.59 \\
\hline Cotinine (ng/mg creatinine) & 1.001 & 0.71 & 1.15 & 0.30 \\
\hline $\mathrm{FE}_{\mathrm{NO}}(\mathrm{ppb})$ & 1.01 & 0.61 & 1.03 & 0.17 \\
\hline Urinary $\mathrm{LTE}_{4}(\mathrm{pg} / \mathrm{mg}$ creatinine) & 1.04 & $0.003^{* * *}$ & 1.00 & 0.81 \\
\hline
\end{tabular}

* P-values calculated using likelihood ratio test

$* *$

$\mathrm{p}<0.05$

$\mathrm{p}<0.01$

1

- all children with exacerbations were female

2

2 - all children with exacerbations were receiving daily inhaled corticosteroid therapy 